\title{
Game Portal Virtual Tugu Pahlawan Dengan Mobile Device Menggunakan Augmented Reality
}

\author{
${ }^{1}$ Muhammad Hafidh Al-Ghifari, ${ }^{2}$ Maulana Rizqi \\ ${ }^{1}$ Program Studi Sistem Komputer, Fakultas Ilmu Komputer, Universitas Narotama \\ e-mail: muhammad.hafidh@mhs.fasilkom.narotama.ac.id \\ ${ }^{2}$ Program Studi Sistem Komputer, Fakultas Ilmu Komputer, Universitas Narotama \\ e-mail: maulana.rizqi@narotama.ac.id
}

\begin{abstract}
Abstrak
Perkembangan aplikasi game virtual telah menjadi daya tarik bagi sebagian orang. Lebih khusus teknologi Augmented Reality dapat memperkenalkan secara langsung bagaimana atmosfer di lokasi atau tempat tertentu, oleh karena itu, dalam penelitian ini kami mencoba membuat aplikasi yang menggabungkan dunia nyata dengan dunia virtual. Dengan menggunakan metode Markerless Augmented Reality yang memungkinkan pengguna untuk menggunakan aplikasi di mana saja dan tidak dibatasi oleh penanda. Dengan aplikasi Augmented Reality juga memungkinkan pengguna merasakan suasana langsung di dunia virtual. Misal seperti Monumen Tugu Pahlawan di Surabaya, dengan teknologi Augmented Reality dapat dimanfaatkan dengan memperkenalkan langsung kepada publik tentang bangunan bersejarah di Surabaya, sehingga orang yang belum pernah ke sana atau yang telah ada di sana dengan menggunakan aplikasi Augmented Reality dapat langsung merasakan seolah-olah mereka berada di Tugu Pahlawan, dan dengan portal virtual akan menghubungkan lokasi pengguna dengan Monumen Tugu Pahlawan dan hanya menggunakan mobile device.
\end{abstract}

Kata kunci: Monumen Tugu Pahlawan, Game Portal Virtual, Augmented Reality, Markerless Tracking

\section{Virtual Portal Game Tugu Pahlawan With Mobile Device Using Augmented Reality}

\begin{abstract}
The development of virtual game applications has become an attraction for some people. More specifically, Augmented Reality technology can introduce directly how the atmosphere in a certain location or place, therefore, in this study we tried to create applications that combine the real world with the virtual world. By using the Markerless Augmented Reality method which allows users to use the application anywhere and is not limited by markers. With the Augmented Reality application it also allows users to feel the atmosphere directly in the virtual world. For example, like the Tugu Pahlawan Monument in Surabaya, Augmented Reality technology can be utilized by introducing directly to the public about historical buildings in Surabaya, so that people who have never been there or who have been there by using the Augmented Reality application can immediately feel as if they are located at Tugu Pahlawan, and with a virtual portal it will connect the user's location with the Tugu Pahlawan Monument and only use a mobile device.
\end{abstract}

Keywords: Tugu Pahlawan Monument, Virtual Portal Game, Augmented Reality, Markerless Tracking 


\section{Pendahuluan}

Augmented Reality adalah salah satu teknologi baru di bidang multimedia. AR ditentukan sebagai teknologi yang dapat menggambarkan dunia nyata dengan dunia virtual, interaktif dalam waktu nyata, dan dalam bentuk animasi 3D. Dengan kata lain, AR adalah teknologi yang mendukung objek virtual dalam dua dimensi (2D) atau tiga dimensi (3D) menjadi lingkungan nyata, kemudian memproyeksikan objek ini secara real time (T.Azuma, 1997).

Dalam AR, informasi yang ditambahkan atau ditambahkan didukung antara objek dan virtual yang telah dirancang sebelumnya (Sin \& Zaman, 2010). pengguna dapat melihat dunia nyata di sekitar mereka dengan membandingkan objek virtual yang dihasilkan oleh komputer (Cawood, 2008).

Proses pembelajaran yang baik harus mengandung interaktif, menyenangkan, menantang, memotivasi dan memberikan lebih banyak ruang bagi siswa untuk mengembangkan kreativitas dan kemandirian, sesuai dengan bakat dan minat siswa. Meskipun guru hanya sebagai fasilitator dalam proses pembelajaran, dan siswa dituntut untuk lebih aktif, guru harus mampu menciptakan suasana belajar yang menyenangkan untuk merangsang siswa agar lebih aktif dalam siswa. Kegiatan belajar yang menyenangkan sangat dipengaruhi oleh berbagai faktor, salah satunya adalah pemilihan media pembelajaran yang digunakan harus mampu menarik minat siswa atau anak untuk belajar, interaktif saat digunakan, tetapi tidak mengurangi esensi dari materi yang disajikan (Ilmawan Mustaqim, 2017).

Teknologi Augmented Reality ini dapat digunakan untuk menyampaikan pengetahuan yang lebih menarik dan bagi publik untuk membuatnya lebih mudah untuk memahami dan memahami langkah-langkah dalam proses pembuatan portal ke lokasi real-time dalam bentuk perangkat seluler berbasis 3D . Kemajuan teknologi yang cepat memiliki dampak kuat pada akademisi. Portal ini terbuat dari kombinasi teknologi Augmented Reality sebagai jenisnya dan perangkat seluler yang dikategorikan sebagai smartphone sebagai sarana aplikasi portal Augmented Reality. 
Salah satu implementasi AR dalam pendidikan dan hiburan adalah penggunaan AR di museum. Pemanfaatan AR di museum adalah momen yang tepat untuk meningkatkan minat pengunjung dalam menjelajahi objek karena sifat interaktif AR.Tugu Pahlawan memiliki ketinggian 41,15 meter yang ternyata berupa lingga atau paku terbalik. Tubuh monumen dalam bentuk 10 lengkungan, dan dibagi menjadi 11 segmen. Namun, ketinggian, bagian, dan lengkungan yang berurutan berarti tanggal 10, November (11) dan 1945. Tanggal-tanggal bersejarah, tidak hanya untuk orang-orang Surabaya, tetapi juga untuk semua orang Indonesia. Monumen Pahlawan dibangun untuk mengenang peristiwa Pertempuran 10 November 1945 di Surabaya (Rizqi et al., 2019).

Berdasarkan penelitian yang akan dilakukan, peneliti memilih lokasi Monumen Tugu Pahlawan sebagai objek, karena Monumen Tugu Pahlawan itu sendiri berfungsi sebagai tujuan wisata dan pembelajaran sejarah bagi penduduk lokal dan internasional.

\section{Pembahasan}

\section{BAHAN DAN METODE}

Pada tahap ini akan menjelaskan tentang bahan yang di gunakan untuk penelitian serta metode yang akan dilakukan oleh penulis.

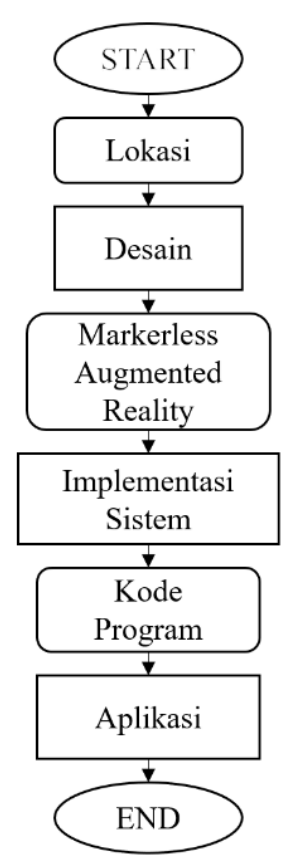

Gambar 1 Diagram Penelitian 


\section{Lokasi}

Lokasi, pada tahap ini peneliti melakukan pengamatan ke lokasi secara langsung untuk dijadikan objek atau bahan dan kemudian melanjutkan penelitian berikutnya.

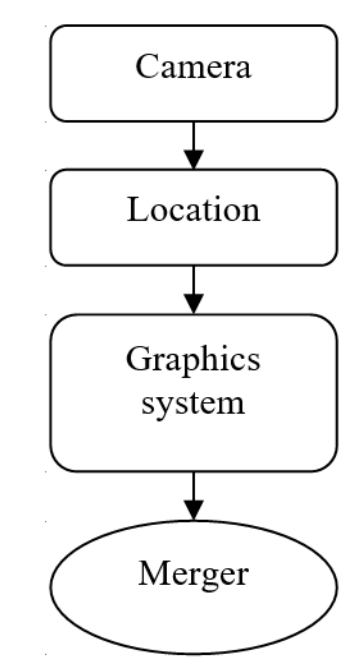

Gambar 2 Penggabungan data

Pada Gambar 2 dapat dilihat bagaimana suatu tempat atau lokasi objek dipindahkan melalui perangkat seluler dan diintegrasikan oleh sistem grafis lalu menjadi objek 3D.

\section{Desain}

Dalam penelitian ini, hasil pengumpulan data Monumen Tugu Pahlawan kemudian di desain untuk membantu penelitian dan melengkapi hasil yang kurang. Dan sekaligus menjelaskan tentang Markerless Augmented Reality. Peneliti mendapatkan data berdasarkan sumber dan menggunakan tipe data sekunder (tidak langsung). setelah selesai mengumpulkan data yang kemudian peneliti selesaikan dengan merancang game aplikasi tersebut.

\section{Markerless Augmented Reality}

Markerless Augmented Reality merupakan salah satu metode Augmented Reality tanpa menggunakan frame marker sebagai obyek yang dideteksi. Dengan adanya Markerless Augmented Reality, maka penggunaan marker sebagai tracking object yang selama ini menghabiskan ruang, akan digantikan dengan gambar, atau permukaan apapun yang berisi dengan tulisan, logo, atau gambar sebagai obyek yang dilacak agar dapat langsung melibatkan obyek yang dilacak (Rizki, 2017). Dan menurut (Daud et al., 2017) yang dilacak tersebut. Seperti yang saat ini dikembangkan oleh perusahaan Augmented 
Realityter besar di dunia Total Immersion dan Qualcomm, mereka telah membuat berbagai macam teknik Markerless Tracking sebagai teknologi andalan mereka seperti.

- $\quad$ Face Tracking

Dengan menggunakan algoritma yang mereka kembangkan, komputer dapat mengenali wajah manusia secara umum dengan cara mengenali posisi mata, hidung, dan mulut manusia, kemudian akan mengabaikan objekobjek lain di sekitarnya seperti pohon, rumah, dan benda-benda lainnya. Teknik ini pernah digunakan di Indonesia pada Pekan Raya Jakarta 2010 dan Toy Story 3 Event.

- 3D Object Tracking

Berbeda dengan Face Tracking yang hanya mengenali wajah manusia secara umum, teknik 3D Object Tracking dapat mengenali semua bentuk benda yang ada disekitar, seperti mobil, meja, televisi, dan lain-lain.

\section{- $\quad$ Motion Tracking}

Pada teknik ini computer dapat menangkap gerakan, Motion Tracking telah mulai digunakan secara ekstensif untuk memproduksi film-film yang mencoba mensimulasikan gerakan. Contohnya pada film Avatar, di mana James Cameron menggunakan teknik ini untuk membuat film tersebut dan menggunakannya secara real time.

- $\quad$ GPS Based Tracking

Pengembangan teknik ini lebih diarahkan pada smartphone, karena teknologi GPS dan kompas yang tertanam pada smartphone tersebut. Dengan memanfaatkan fitur GPS yang berfungsi sebagai penentu lokasi pengguna pada saat itu berada sehingga lokasi.

\section{Implementasi Sistem}

Pada tahap implementasi, percobaan dilakukan pada sistem dalam bentuk merekam hasil yang dihasilkan oleh Aplikasi untuk mendukung Ground Plane,

\section{Kode Program}

Pada tahap ini secara singkat menjelaskan masalah pengkodean dalam aplikasi portal Augmented Reality, jika kita melihat secara rinci sebenarnya ada banyak kode untuk pemrograman portal. namun kali ini hanya membahas Markerless Augmented Reality. 


\section{Aplikasi}

Dalam aplikasi ini akan dijelaskan sedikit bagaimana cara kerja dari aplikasi Augmented Reality tersebut pada mobile device.

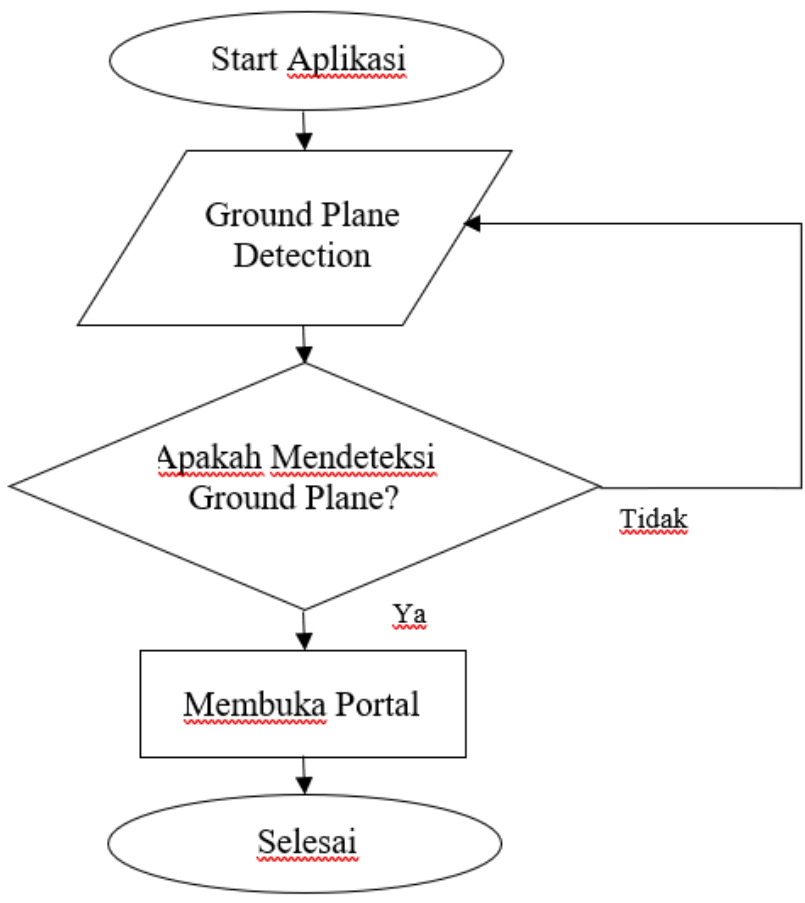

Gambar 3 Diagram Aplikasi

- Start Application, Pada tahap ini kita akan mulai dengan membuka aplikasi di mana aplikasi tersebut menggunakan berbagai tampilan.

- Ground Plane Detection, pada tahap Ground Plane Detection akan menampilkan semacam titik seperti mencari tempat yang cocok untuk mulai membuka Portal.

- Is it Detecting Ground Plane, Pada tahap ini terjadi looping, ketika Ground Plane telah terdeteksi, lalu segera membuka / membuka Portal, tetapi jika tidak dalam hal ini tidak akan memunculkan apa pun kecuali hanya titik.

- Open a Portal, Pada tahap terakhir ini ketika telah melewati tahap di atas tersebut, apliakasi akan segera memunculkan portal yang akan membawa ke dunia virtual.

\section{HASIL}

Pada bab ini akan menjelaskan hasil dari penelitian ini dan penjelasan yang lain yang 
berkaitan juga dengan percobaan yang telah dilakukan. Berikut beberapa penjelasan yang akan peneliti paparkan.

\section{D Objek}

Sebuah ruang atau benda yang memiliki panjang, lebar dan tinggi yang memiliki bentuk. Konsep tiga dimensi atau 3D menunjukkan suatu objek atau ruang memiliki tiga dimensi geometris yang terdiri dari: kedalaman, luas dan tinggi.

\section{Monumen Tugu Pahlawan}

Bangunan bersejarah dari kota Surabaya ini memiliki ketertarikan sendiri bagi wisatawan yang ingin singgah dan sekaligus menjadi foto bersama keluarga, teman dan lain-lain. Di Monumen Tugu pahlawan juga memiliki banyak sekali sejarah yang terjadi di surabaya, mulai dari perjuangan dan sejarah lain nya. Dan ini adalah tempat yang akan digunakan para peneliti sebagai objek yang telah diamati oleh peneliti.

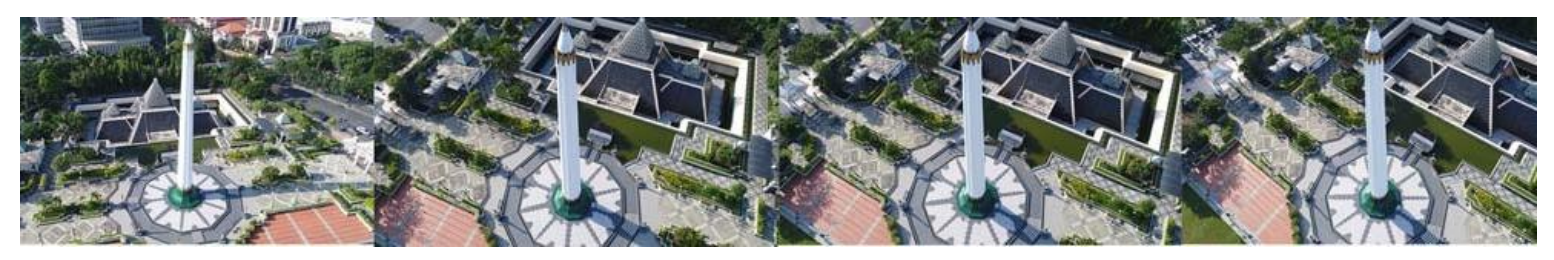

Gambar 4 Monumen Tugu Pahlawan (Rizqi et al., 2019)

Pada gambar 4 yang pertama diambil dari depan menggunakan kamera drone dari tengah lapangan, dan pada ketinggian diperkirakan sekitar 50m. Dan yang di sebelahnya lagi diambil dari samping, memperlihatkan lebih jelas bentuk museum yang ada di belakang Tugu dan menampilkan lebih banyak bangunan yang ada di dalam Monumen Tugu Pahlawan tersebut.

\section{3D Models}

3D Model termasuk menggambarkan bentuk objek 3D, tata letak dan animasi yang menggambarkan gerakan dan tata letak objek 3D. 


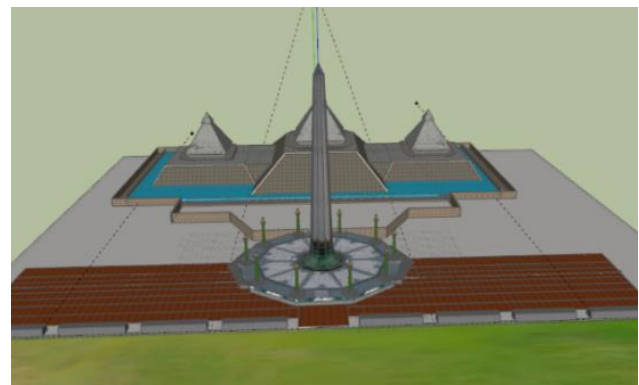

Gambar 5 3D Model Monumen Tugu Pahlawan

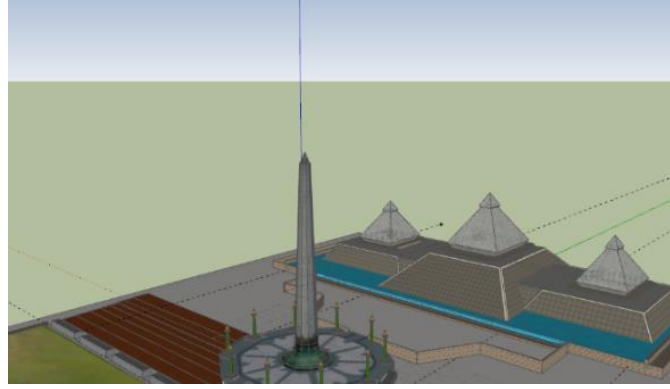

Gambar 6 3D Model Monumen Tugu Pahlawan

Pada Gambar 5 dan 6 adalah hasil dari pembuatan ulang Monumen Tugu Pahlawan menggunakan SketchUp yang diambil dari tampilan depan yang menunjukkan area di sekitar Monumen saja. Dan di samping nya juga hasil yang sama, pembuatan ulang Monumen Tugu Pahlawan menggunakan SketchUp yang diambil dari tampilan samping yang menunjukkan area sisi Monumen dan museum.

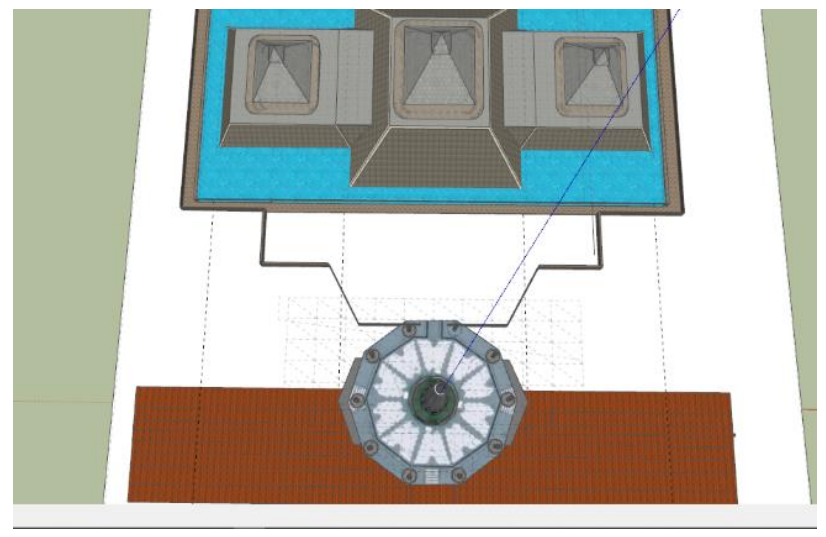

Gambar 7 3D Model Monumen Tugu Pahlawan (tampilan atas)

Pada gambar 7 adalah hasil pemodelan yang diambil dari tampilan atas yang menunjukkan Monumen Tugu Pahlawan dan museum dari atas, dan jika di lihat pada bagian atas mungkin putih karna dari area tersebut terjadi perubahan pada material yang di gunakan sehingga warna nya akan tampak berubah jika di lihat dari atas.

\section{3D Model Portal}

Portal yang akan menghubungkan antara pengguna dan objek 3D Monumen Tugu Pahlawan. 


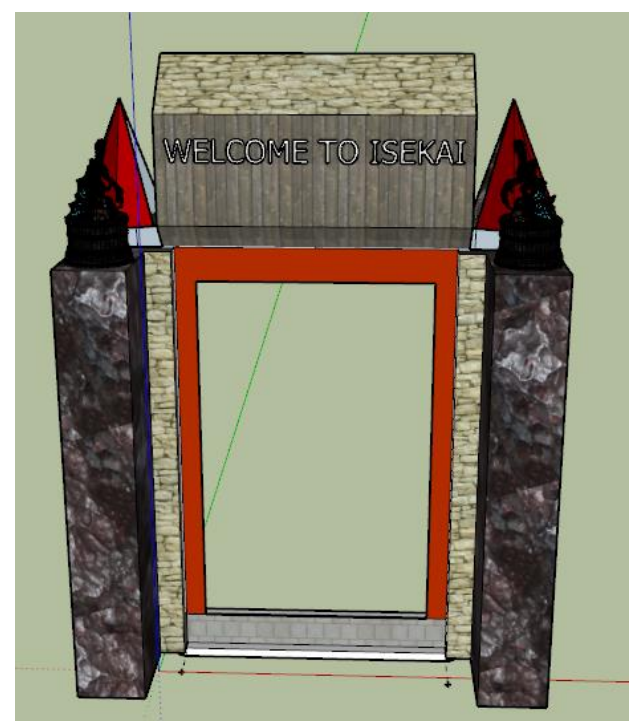

Gambar 8 3D Portal

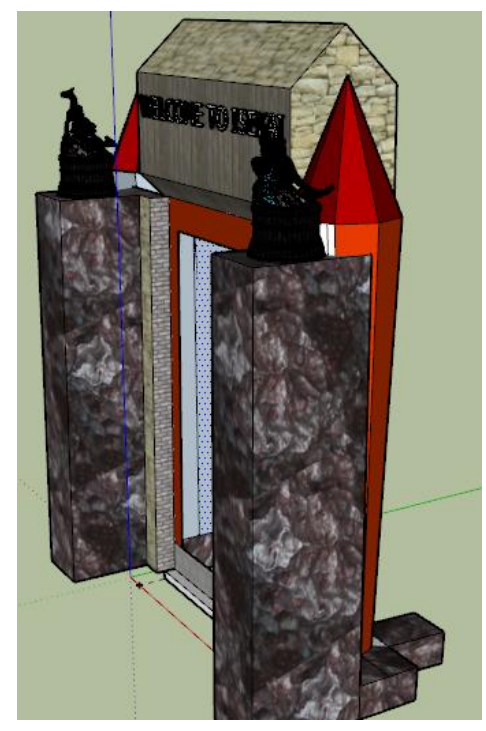

Gambar 9 3D Portal

Gambar 8 dan 9 adalah hasil dari pemodelan portal yang dibuat di tampilan SketchUp dari depan dan yang akan menjadi pintu ke Monumen Tugu Pahlawan. Dan di sebelahnya juga hasil pemodelan portal 3D ditampilkan dari samping dan di sisi itu menunjukkan dinding yang kemudian ditambahkan ke bahan-bahan di SketchUp agar terlihat nyata.

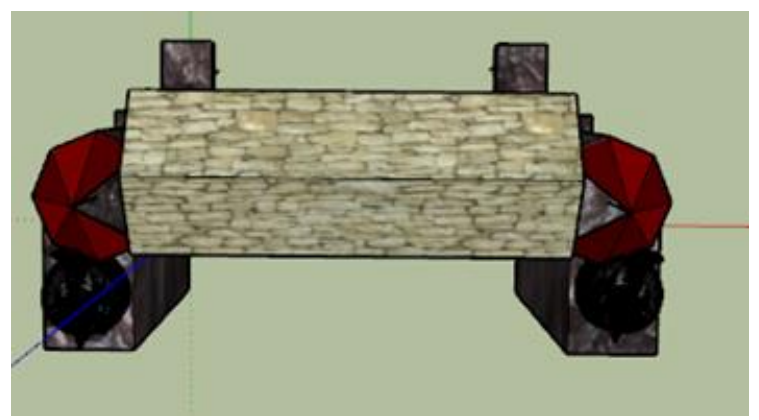

Gambar 10 3D Portal (tampilan atas)

Gambar 10 menunjukkan dari atas dan menunjukkan atap portal dan sama seperti gambar di atas atap ditambahkan ke materi di SketchUp sehingga terlihat nyata. Dan hasil tersebut akan di gabungkan dengan objek 3D Monumen Tugu Pahlawan.

\section{Mobile Device Support ARCore}

ARCore adalah platform Google untuk membangun pengalaman Augmented Reality. Dengan menggunakan berbagai API, ARCore memungkinkan ponsel Anda merasakan 
lingkungannya, memahami dunia, dan berinteraksi dengan informasi. tidak semua ponsel dapat digunakan untuk Aplikasi Augmented Reality, hanya beberapa perangkat yang dapat digunakan untuk Aplikasi untuk terjadinya interaksi antar pemain, sehingga terdapat persaingan dan komunikasi satu sama lain.

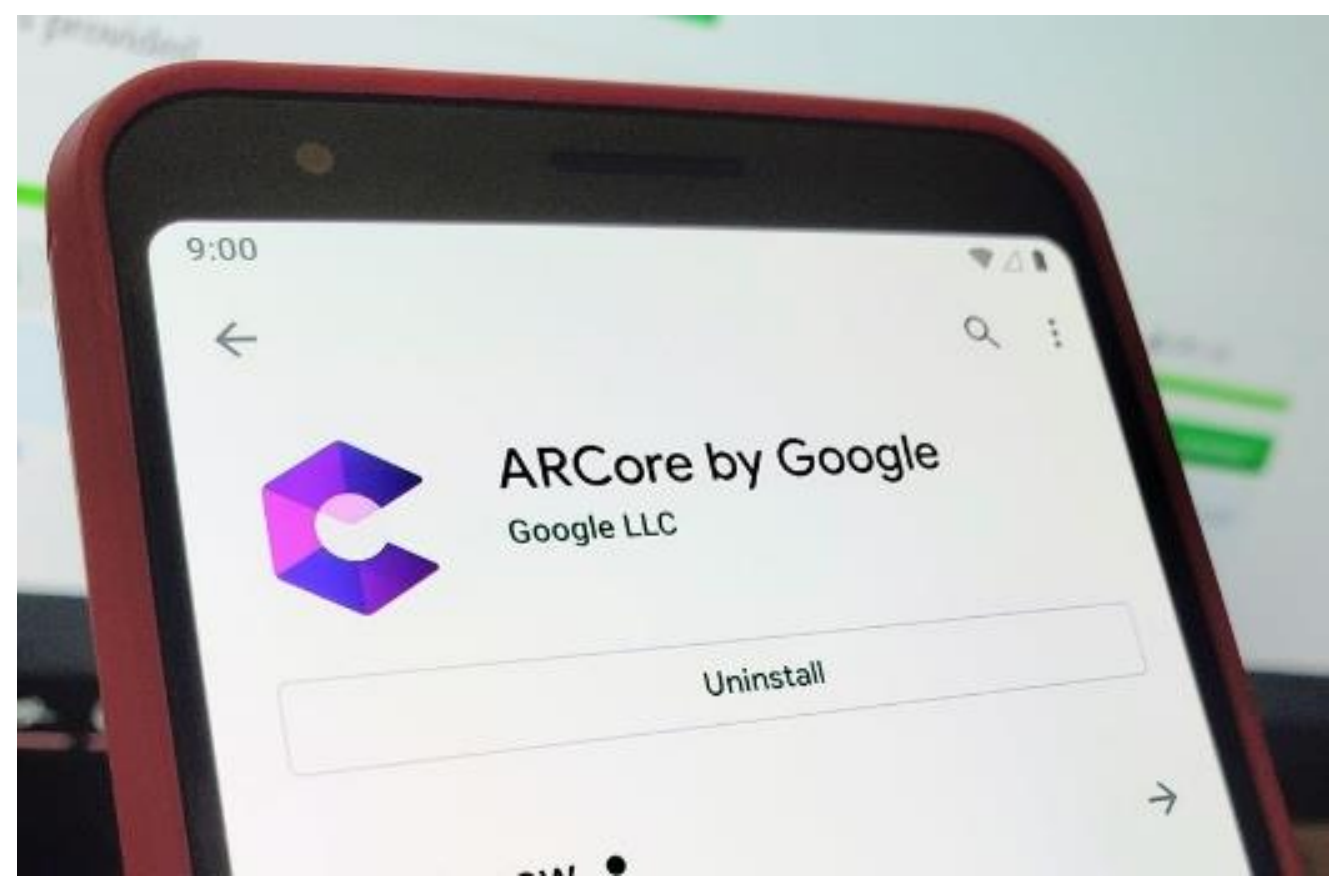

Gambar 11 ARCore (PERKINS, 2019)

\section{Vuforia Engine}

Platform yang paling banyak digunakan untuk pengembangan AR, dengan dukungan untuk ponsel, tablet, dan kacamata terkemuka. Pengembang dapat dengan mudah menambahkan fungsionalitas visi komputer canggih ke aplikasi Android, iOS dan UWP, untuk menciptakan pengalaman AR yang secara realistis berinteraksi dengan objek dan lingkungan.

\section{Vuforia Ground Plane}

Sebuah tanda yang muncul pada area/permukaan saat mulai mensimulasikan objek Augmented Reality 


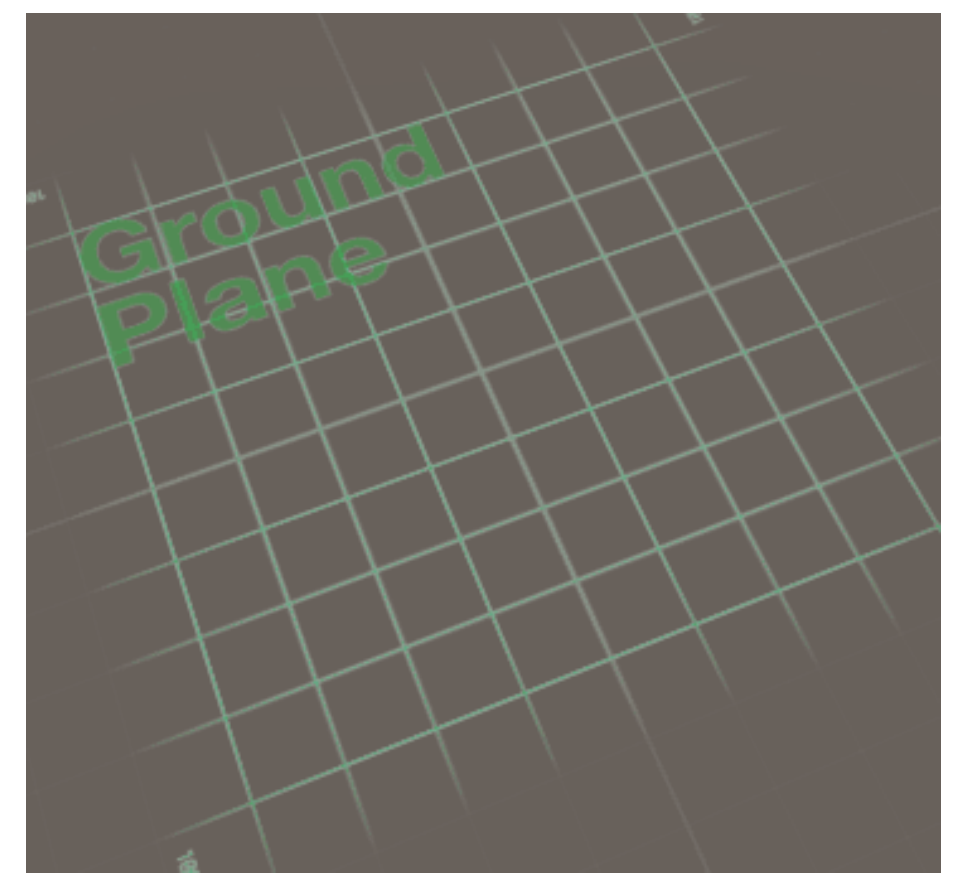

Gambar 12 Ground Plane (PTC Inc., 2017)

Dapat dilihat pada Gambar 16. memungkinkan konten digital ditempatkan pada permukaan horizontal di lingkungan Anda, seperti lantai dan permukaan meja. Ini memperluas Vuforia Smart Terrain untuk mendukung deteksi dan pelacakan permukaan horizontal dan juga memungkinkan Anda untuk menempatkan konten di udara.

\section{Smart Terrain}

sebuah fitur yang memberikan aplikasi kecerdasan dan kesadaran objek di suatu area atau permukaan. 


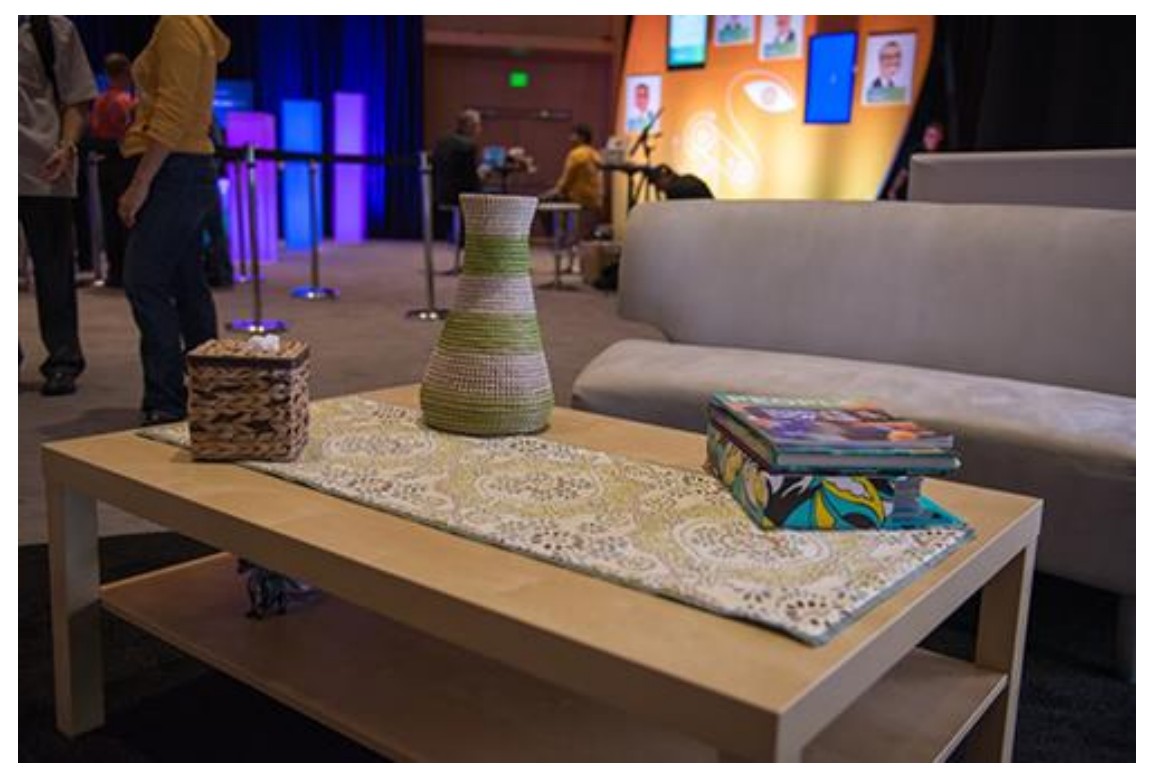

Gambar 13 Smart Terrain pada meja (Qualcomm, 2013)

Mengizinkan konten digital ditempatkan pada permukaan horizontal di lingkungan Anda, seperti permukaan lantai dan meja dan untuk mendukung deteksi dan pelacakan permukaan horizontal, dan juga memungkinkan Anda menempatkan konten di udara.

\section{Kode Program}

Setelah semua tahap di atas di lakukan, maka akan di lakukan adalah proses menerjemahkan desain ke dalam bahasa yang dapat dipahami oleh komputer yang di sebut dengan kode program.

\section{AR Controller Portal}

diperlukan kode untuk membuat 3D portal bekerja, karena itu memerlukan sebuah program untuk membuatnya bekerja dengan sempurna dan membuatnya terlihat seperti nyata. 


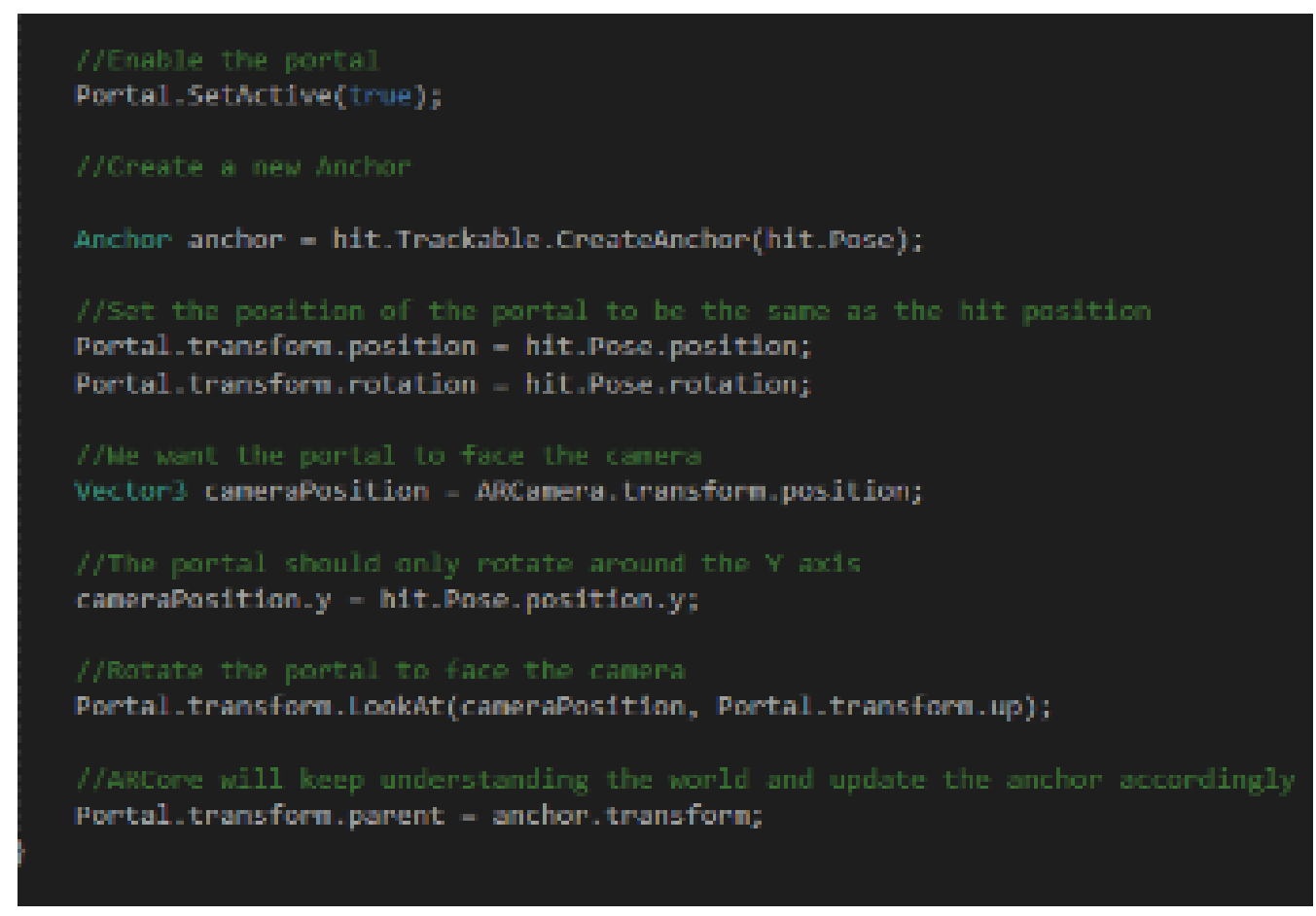

Gambar 14 Mengaktifkan Portal

\section{Call Object}

untuk memanggil objek 3D juga ada kode program nya dan diperlukan untuk memprogram objek 3D agar objek 3D tersebut bisa muncul secara langsung ketika portal tersebut muncul pada permukaan.

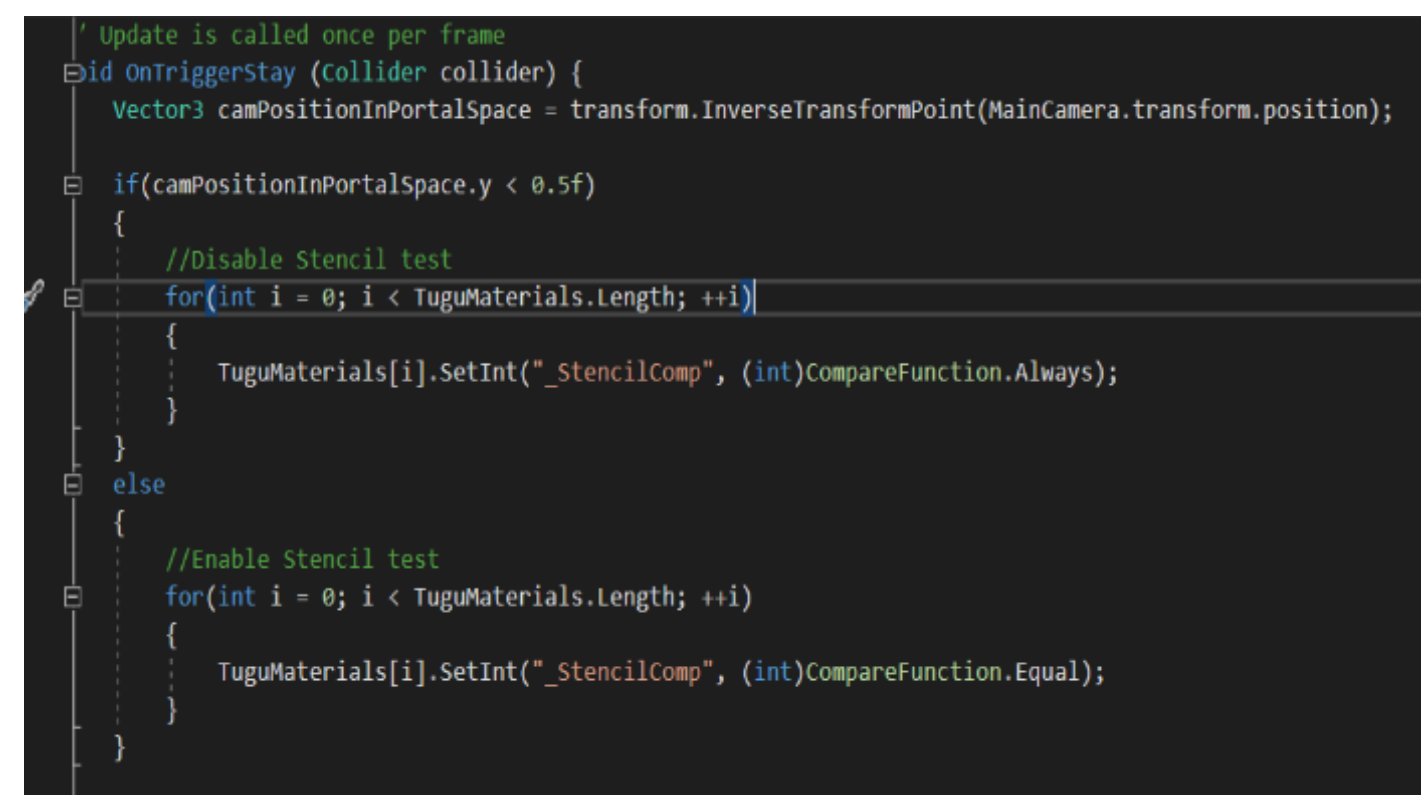

Gambar 15 Memanggil objek 
Untuk mengaktifkan portal dan objek 3D cukup ikuti kode program di atas. Dalam kode program di atas hanya menjelaskan beberapa mengaktifkan portal dan objek 3D, meskipun demikian banyak sekali cara agar portal dan objek 3D bekerja dan banyak juga kode program untuk mengaktifkan portal dan objek 3D tersebut.

Monumen Tugu Pahlawan yang merupakan objek utama didesain ulang menggunakan perangkat lunak SketchUp. dan sama hal nya dengan Monumen Tugu Pahlawan, portal yang berfungsi sebagai penghubung antara dunia nyata dan objek 3D Monumen Tugu Pahlawan dirancang menggunakan software SketchUp dan di dalam software SketchUp juga ada banyak sekali bahan yang digunakan untuk menambahkan material menjadi objek yang tampak seperti nyata. juga untuk menambahka Portal dan Monumen Tugu Pahlawan terlihat lebih bagus.

Setelah Portal Monumen dan Pahlawan dirancang menggunakan SketchUp, kemudian diimpor ke Unity, dan setelah semua selesai, kemudian di export dalam bentuk aplikasi. Di Unity, mulailah di program bagaimana portal bekerja saat aplikasi terbuka, portal berjalan dengan baik dan di Unity juga perlu perhatikan di setiap programnya, sehingga kemungkinan terjadi nya sebuah bug kecil dan tidak ada kesalahan.

Kemudian setelah dibangun ke dalam aplikasi Augmented Reality Portal, aplikasi tersebut kemudian diuji di lapangan terbuka dan diuji di ruangan kecil. Aplikasi Augmented Reality ini memiliki beberapa mekanisme, yaitu sentuh layar, deteksi Ground Plane, Portal muncul, dan bergerak.
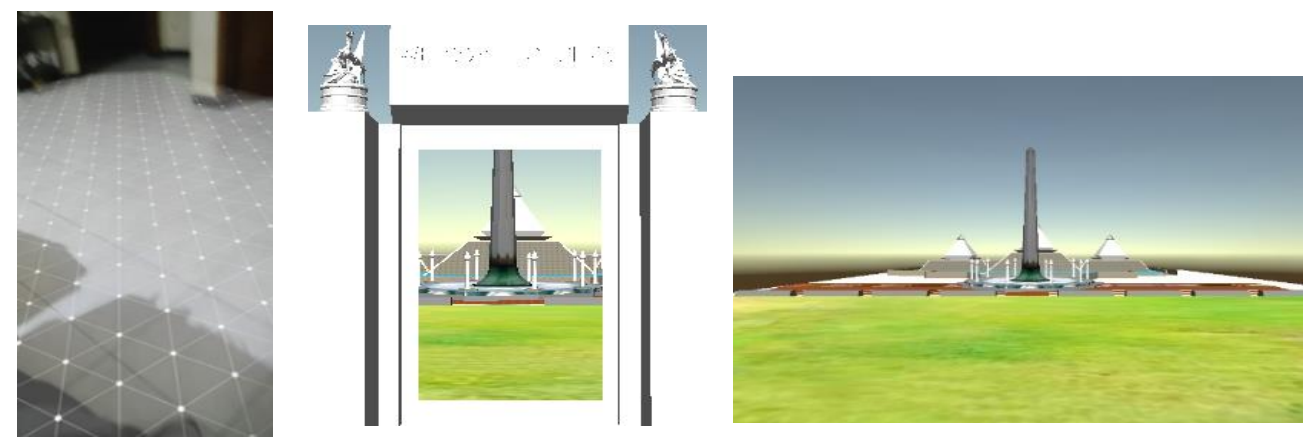

Gambar 16 Aplikasi Game Portal 


\section{Kesimpulan}

Berdasarkan penelitian ini, dapat disimpulkan bahwa aplikasi game portal Augmented Reality dapat diterapkan untuk semua area termasuk area karena menggunakan Augmented Reality tanpa marker. Tidak semua perangkat seluler dapat digunakan, hanya perangkat seluler yang memiliki dukungan ARCore hanya dapat menggunakan aplikasi game portal Augmented Reality. untuk kedepan nya, desain Portal dan Monumen Tugu Pahlawan dapat dikembangkan lagi, sehingga desain portal menjadi lebih baik dan lebih baik dari sekarang, dan untuk Monumen Tugu Pahlawan itu sendiri semakin ditingkatkan dan ditambahkan ke lingkungan sekitarnya. 


\section{Referensi}

Cawood, S. dan M. F. (2008). Extracted from: Augmented Reality A Practical Guide. Augmented Reality A Practical Guide.

Daud, J., Yulsilviana, E., \& Setiawan, S. (2017). PENERAPAN AUGMENTED REALITY MENGGUNAKAN METODE MARKERLESS TRACKING SEBAGAI SARANA PROMOSI PERUMAHAN PADA PT . TRI JAYA PASER BERBASIS ANDROID. 1(1), 6 .

Ilmawan Mustaqim, N. K. (2017). Pengembangan Media Pembelajaran Berbasis Augmented Reality. Lentera Pendidikan: Jurnal Ilmu Tarbiyah dan Keguruan, 21(1), 36-48. https://doi.org/10.24252/lp.2018v21n1i6

PERKINS, S. (2019). Enable ARCore on Any Android Phone. android.gadgethacks.com.

PTC Inc. (2017). Ground Plane User Guide. library.vuforia.com. https://library.vuforia.com/articles/Training/ground-plane-guide.html

Qualcomm. (2013). Hands On: Vuforia “Smart Terrain.” www.qualcomm.com.

Rizki, Y. (2017). Markerless Augmented Reality Pada Perangkat Android. E-Journal Teknik Informatika, 2(1), 35-46. https://doi.org/10.13140/RG.2.2.31230.02889

Rizqi, M., Gumelar, A. B., Prima, D. A., Zikkv, M., \& Prasetya, N. I. (2019). Surabaya Heroes Monument Topographic Data Acquisition Using Quad-Rotor Unmanned Aerial Vehicle (UAV). Proceedings - 2019 International Seminar on Application for Technology of Information and Communication: Industry 4.0: Retrospect, Prospect, and Challenges, iSemantic 2019, 366-371. https://doi.org/10.1109/ISEMANTIC.2019.8884309

Sin, A. K., \& Zaman, H. B. (2010). Live Solar System (LSS): Evaluation of an Augmented Reality book-based educational tool. Proceedings 2010 International Symposium on Information Technology - Visual Informatics, ITSim'10, 1. https://doi.org/10.1109/ITSIM.2010.5561320

T.Azuma, R. (1997). A Survey of Augmented Reality. Massachusetts institute ofTTechnology, 42(3), 355-384. https://doi.org/10.1016/j.chaos.2009.03.056 